\title{
Comparison efficacy and side effects of combined cystone and hydrochlorothiazide with cystone monotherapy in treatment and passage of upper urinary stones; a randomized clinical trial
}

\author{
Sadrollah Mehrabi ${ }^{*}$, Parisa Behnam ${ }^{2}$, Leila Manzouri ${ }^{1}$, Amir Mehrabi $^{2}$ \\ ${ }^{1}$ Social Determinants of Health Research Center, Yasuj University of Medical Sciences, Yasuj, Iran \\ ${ }^{2}$ Student Research Committee, Yasuj University of Medical Sciences, Yasuj, Iran
}

\section{A R T I C L E I N F O}

Article Type:

Original

\section{Article History:}

Received: 1 January 2019

Accepted: 7 May 2019

Published online: 23 May 2019

\section{Keywords:}

Urinary calculi

Therapy

Drug therapy

Cystone

Hydrochlorothiazide

\begin{abstract}
A B S T R A C T
Introduction: Urinary stones are one of the most common and painful diseases of humans after urinary tract infections and prostate diseases.

Objectives: The aim of this study was comparing the efficacy and complications of combined cystone and hydrochlorothiazide with cystone monotherapy in the treatment of upper urinary stones.

Patients and Methods: In this randomized clinical trial 80 patients older than 15 years old with renal and ureteral stones less than $10 \mathrm{~mm}$ after taking informed consent form were allocated randomly in one of two groups. Patients with azotemia, hydronephrosis, bothersome pain and pregnant women were excluded. In the first group, combinations of cystone and hydrochlorothiazide tablets (every 12 hours, two $100 \mathrm{mg}$ cystone and $25 \mathrm{mg}$ hydrochlorothiazide) were prescribed. In the second group, cystone were prescribed as the first group. One month later, patients were followed by kidney, ureter, and bladder x-ray (KUB) and ultrasonography and the success of treatment was determined by changing the size of stones and report of stone passage by the patients. All data were collected and analyzed by SPSS software version 23 and statistical tests.

Results: The mean age of the patients in combined and single groups were $48.02 \pm 13.72$ and $44.15 \pm 14.86(\mathrm{P}=0.24)$ years respectively. The mean size of stone after treatment in two groups was $1.72 \pm 0.98$ and $1.85 \pm 0.78 \mathrm{~mm}$ respectively $(P=0.53)$. Regarding efficacy of combined and single group, more than $90 \%$ of the patients reported stones passage after the intervention $(P=0.06)$. There were no significant differences in mean blood urea $(P=0.38)$ and serum creatinine $(P=0.53)$ after treatment in two groups.

Conclusion: The results of this study showed that combination of cystone and hydrochlorothiazide do not increase the efficacy of cystone in treatment and passage of urinary stones, although in both groups stone passage significantly increased.

Trial Registration: Registration of this randomized clinical trial has been approved (approval date; 2018-01-10,) in Iranian registry of clinical trials ( identifier: IRCT20081011001323N15; https://irct.ir/trial/29499; Ethics committee reference number; IR.YUMS.REC.1396.156).
\end{abstract}

Implication for health policy/practice/research/medical education:

Regarding the high prevalence of urinary stones and their complications, in this randomized clinical trial 80 patients with urinary stones were allocated in two groups to compare the effect of combined cystone and hydrochlorothiazide with cystone monotherapy on the treatment of upper urinary stones. Results of this study showed that combination of cystone and hydrochlorothiazide do not increase the efficacy of cystone in treatment and passage of urinary stones.

Please cite this paper as: Mehrabi S, Behnam P, Manzouri L, Mehrabi A. Comparison efficacy and side effects of combined cystone and hydrochlorothiazide with cystone monotherapy in treatment and passage of upper urinary stones. J Renal Inj Prev. 2019;8(3):211-215. DOI: 10.15171/jrip.2019.39. 


\section{Introduction}

Urinary stones are one of the most common and painful diseases of humans after urinary tract infections and prostate diseases. It is the third most common disease of genitourinary tract that affects many communities around the world (1). The probability that each person makes a urinary stone during his/her lifetime is on average about $5 \%$ to $12 \%(1,2)$. The risk factors involved in the formation of urinary stones include age, gender, diet, geographical location, genetic predisposition, urinary tract dysfunction and anatomical disorders of the urinary tract (1,3-4).

Over the past two decades, major improvements have been made in the removal of urinary tract stones, including ureteroscopy, extracorporeal shockwave lithotripsy and percutaneous nephrolithotomy $(1,5)$. Regarding the recurrence of urinary tract stones in about $50 \%$ of patients over a period of 5 years, urinary tract surgery and lithotripsy are incomplete managements and prevention of recurrence is also important. Therefore, a combination of surgical and pharmaceutical procedures for complete control of the disease is required $(3,5)$.

Drugs such as calcium channel blockers, alphaadrenergic blockers and steroids are administered for treat urinary stones, but long-term use of them has significant side effects $(1,3)$. It is claimed that a number of herbs and their compounds have beneficial effects on prevention and treatment of urinary tract stones $(6,7)$. Cystone is a mineral plant compound specifically designed and developed for the prevention and treatment of urinary stones and has been claimed to play a role in facilitating stone passage (8-11).

Cystone prevents accumulation, deposition, and oversaturation of chemicals such as oxalic acid and calcium hydroxyproline in urine, and by dissolving mucin; it prevents the mixing of crystal particles, and in the urinary tract helps expulsion of small stones. $(9,12,13)$.

Hydrochlorothiazide is a special inhibitor of sodium and chloride in distal convoluted tubule that reduces calcium urinary excretion and is an effective treatment for the formation of calcium stones and preventing the formation of urinary stones (14-16).

\section{Objectives}

Regarding the high prevalence of urinary stones and their complications, the present study was conducted to compare the effect of combined cystone and hydrochlorothiazide with cystone monotherapy on the treatment of renal and ureteral stones.

\section{Patients and Methods}

In this randomized clinical trial 80 patients with renal and ureteral stones with a size of $4-10 \mathrm{~mm}$ who were referred to the urology clinic and were older than 15 years after taking informed consent form and approval of ethics committee of university were allocated randomly by simple sampling method to one of two groups. All patients completed history and physical examination, and basic serum samples including PT, PTT, CBC, Hb, Na, K, renal function tests (BUN, Cr), and complete urinalysis and urine culture were conducted. The patients with severe cardiovascular or pulmonary disease, coagulation disorders, uncontrolled blood pressure, urinary tract infection, azotemia, hydronephrosis and bothersome pain, pregnant women and those who had a history of drug or medicinal allergy were excluded from the study. In two groups, patients were recommended to drink 10-12 glasses of water per day. In the first group, a combination of cystone tablets (every 12 hours, two pills [200 mg] with a glass of water) and hydrochlorothiazide (every 12 hours, half a tablet [25 mg] with a glass of water) was used. In the second group, cystone tablets (every 12 hours, two tablets with a glass of water) were taken. Two groups were received diclofenac for pain relief and, if not responding to the medication or have indications of intervention, the standard treatment was performed. It was also recommended that patients take at least 30 minutes of exercise and walking every day. One month later, patients were re-examined and kidney, ureter, and bladder (KUB) $\mathrm{X}$-ray or ultrasound was performed and the success of the treatment was determined by changing the size of the stone and the presence of remaining residual and the rate of stone passage by the patients. The study design is shown in Figure 1.

\section{Ethical issues}

The research followed the tenets of the Declaration of Helsinki. Informed consent was obtained. The research was approved by the ethical committee of Yasuj University of Medical Sciences (Ethic code: IR.YUMS.REC.1396.156) and was registered in Iranian Registry of Clinical Trials (identifier: IRCT20081011001323N15; https://irct.ir/ trial/29499). This manuscript was extracted from M.D., thesis of Parisa Behnam in Yasuj University of Medical Sciences.

\section{Statistical analysis}

All data were collected and analyzed by SPSS 21 software using descriptive (frequency, mean and standard deviation) and analytical (independent sample $t$ test and chi-square test) statistics. $P<0.05$ was considered as a significant level.

\section{Results}

In this study 80 patients were eligible to enter the study. From the group receiving cystone 2 patients and from the group receiving cystone and hydrochlorothiazide, 3 patients were excluded due to lost of follow up. There were no differences between the two groups in terms of demographic characteristics such as age, gender, size and number of stones before surgery. The mean age of the 


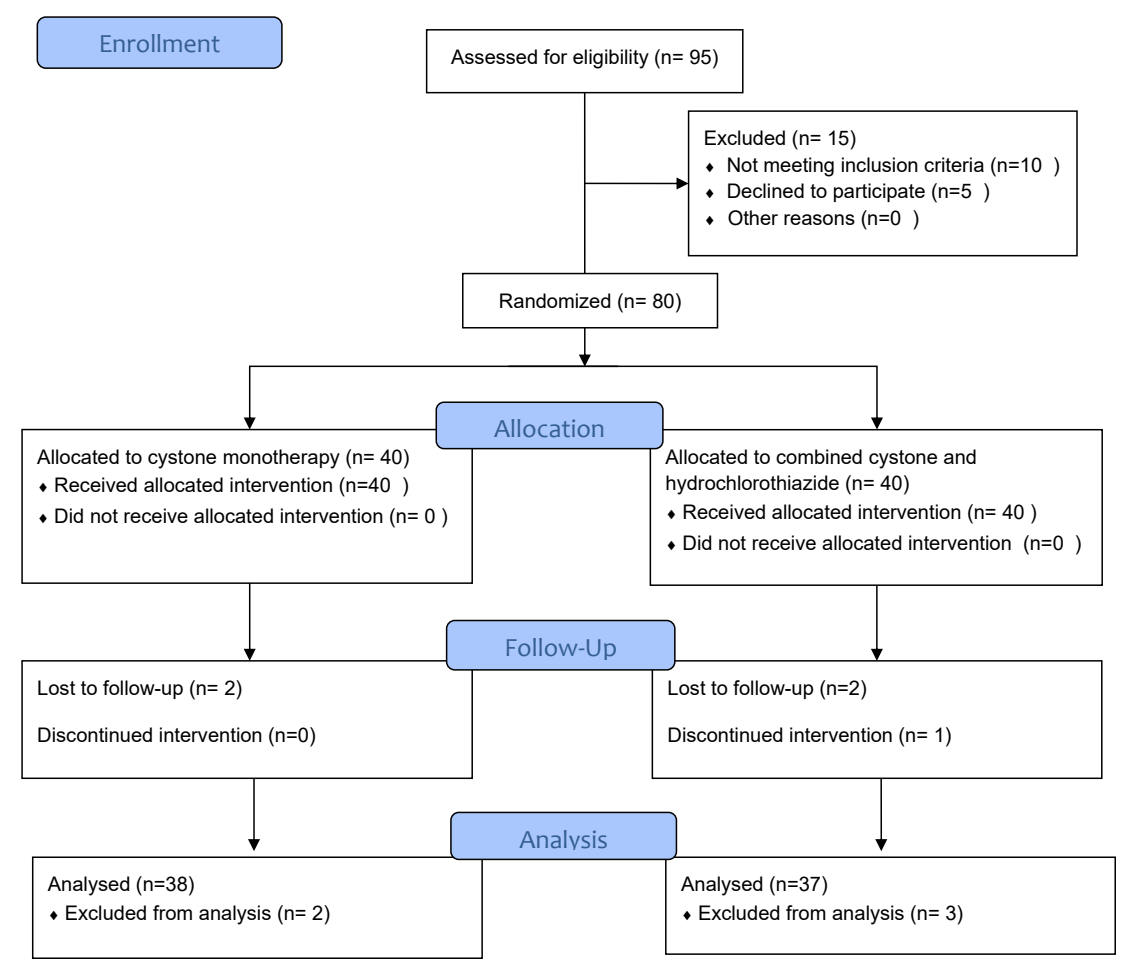

Figure 1. Schematic flow diagram of the study.

patients in two groups were $48.02 \pm 13.72$ and $44.15 \pm 14.86$ years respectively $(P=0.24)$. The mean size of the stone before treatment in the two groups was not significantly different $(P=0.57$; Table 1$)$.

Regarding frequency distribution of stone location in two groups, in the cystone group 24 patients (51.1\%) and in the combination group in 23 patients (48.9\%) they had more than one stone location, which was no significant statistical difference between them $(P=0.69)$. The mean size of stones after treatment has shown in Table 2. There was no significant difference based on mean stone size between two groups $(P=0.53)$.

Regarding efficacy of cystone and the combination of cystone and hydrochlorothiazide, more than $90 \%$ of the patients reported stone passage after the intervention, but no significant differences were observed between the two groups $(P=0.06$; Table 3$)$.

There were no reports of side effects in two groups. The mean blood urea in the two groups after the treatment in the single and combination groups was $19.13 \pm 2.62$

Table 1. Frequency distribution of patients regarding mean stone size before treatment in two groups

\begin{tabular}{lccc}
\hline & \multicolumn{2}{c}{ Variable } & \\
\cline { 2 - 2 } Groups & $\begin{array}{c}\text { Mean stone size } \pm \text { SD } \\
(\mathbf{m m})\end{array}$ & P value & 95\% Cl \\
\hline $\begin{array}{l}\text { Cystone } \\
\begin{array}{l}\text { Cystone and } \\
\text { hydrochlorothiazide }\end{array}\end{array}$ & $6.24 \pm 1.24$ & & \\
\hline
\end{tabular}

$\mathrm{mg} / \mathrm{dL}$ and $19.67 \pm 2.71 \mathrm{mg} / \mathrm{dL}$ respectively $(P=0.38)$. Additionally, mean serum creatinine after treatment in both groups was $1.32 \pm 1.13 \mathrm{mg} / \mathrm{dL}$ and $0.97 \pm 0.22 \mathrm{mg} / \mathrm{dL}$ $(P=0.53)$, which shows no significant difference of renal function between the groups.

\section{Discussion}

Different factors are effective in the clearance of the urinary tract of stone and its passage, such as mechanical stimulation, diuretics, solvent material, alkaline

Table 2. Frequency distribution of patients regarding mean stone size after treatment in two groups

\begin{tabular}{lccc}
\hline & \multicolumn{2}{c}{ Variable } & \\
\cline { 2 - 2 } Groups & $\begin{array}{c}\text { Mean stone size } \pm \text { SD } \\
(\mathbf{m m})\end{array}$ & P value & $\mathbf{9 5 \%} \mathrm{Cl}$ \\
\hline $\begin{array}{l}\text { Cystone } \\
\begin{array}{l}\text { Cystone and } \\
\text { hydrochlorothiazide }\end{array}\end{array}$ & $4.28 \pm 1.24$ & & \\
\hline
\end{tabular}

Table 3. Frequency distribution of patients in two groups according to stone passage after treatment

\begin{tabular}{lccc}
\hline & \multicolumn{2}{c}{ Variable } & \\
\cline { 2 - 2 } Groups & $\begin{array}{c}\text { Mean stone size } \pm \text { SD } \\
(\mathbf{m m})\end{array}$ & P value & df \\
\hline $\begin{array}{l}\text { Cystone } \\
\begin{array}{l}\text { Cystone and } \\
\text { hydrochlorothiazide }\end{array}\end{array}$ & $1.85 \pm 0.78$ & 0.06 & 2 \\
\hline
\end{tabular}


substances, intestinal absorption inhibitors, uric acid lowering drug and urease inhibitors $(1,3,14)$. It is detected that a number of medicinal herbs and their compounds have beneficial effects on prevention of urinary stones and their expulsion $(8,15)$. Cystone is a commercial product of Himalaya, a mineral plant compound specifically designed and developed for the prevention and treatment of ureter stones, and has been claimed to play a role in facilitating stone excretion $(8,11)$. Cystone disintegrates the stones and crystals through the effect on mucin that binds the particles together $(8,12)$.

Thiazides (hydrochlorothiazide), which are the main examples of this group, are derivatives of sulfonamide. They are active in oral form and have a half-life of 6-12 hours. Their main function is to inhibit the transfer of sodium chloride in the inferior part of the convoluted tubule (16). Full doses of thiazides cause moderate but persistent diuresis of sodium and chloride that increases the exchange of sodium-calcium in the vascular membrane, thus increasing calcium reuptake from urine and decreasing calcium excretion $(16,17)$.

Thiazides do not affect the normal absorption of calcium from the intestine and reduce the urinary calcium in absorptive hypercalciuria, and therefore, chronic formation of calcium stones can be controlled with thiazides (17). Calcium excretion in $50 \%$ of patients reaches levels of pretreatment after $4-5$ years $(3,18)$. The aim of our study was to compare the effect of combined cystone and hydrochlorothiazide versus cystone alone on the treatment and passage of urinary stones in patients referred to the urology clinic.

The results of this study showed no significant difference between the two groups regarding the mean size of stones, number of stone location and the frequency of stone passage. Although in both groups the size of stone was reduced after treatment, there was no significant difference between them.

Kumar et al showed that cystone contributed to the excretion of stones in 18 patients (66.7\%), while the rate of excretion in placebo was $10 \%$ (3 patients). The mean time for stone expulsion in patients treated with cystone was 12.3 days (range 7-20 days), which was accompanied by a significant reduction in the size of the stone, while there was no decrease in the size of the stone in the placebo group. Furthermore, significant improvement in clinical symptoms of stones passage such as hematuria, frequency and flank tenderness were seen in the cystone group. Accordingly they observed a significant decrease in serum uric acid levels (8). Moreover, Karamakar and Patki found that cystone caused a significant reduction in 24-hour urinary excretion of oxalate, uric acid; calcium, magnesium, and phosphorus with a significant increase in urinary volume (9). Other studies have also reported the same effects for cystone (10-13). In our study, although we did not use placebo drug, most patients that were treated with cystone reported passage of stone and the size of stones decreased in ultrasound that was consistent with the results of the previous studies. Some previous studies have shown that hydrochlorothiazide is a treatment for some type of hypercalciuria that helps prevention and treatment of urinary stones, which is not consistent with the findings of the present study $(16,19)$. Yosefi et al conducted a study on the effects of hydrochlorothiazide on prevention of recurrent urinary tract infections in children with idiopathic hypercalciuria. Their findings showed that all patients treated with hydrochlorothiazide were soft-calcified. In each group, recurrence of urinary tract infection was $34 \%$ (17 cases) which was not statistically significant. Therefore, the results of this study rejected the effect of hypercalciuria treatment in the prevention of infection (17). Therefore, the relationship between these two diseases and their therapeutic decisions requires more precise studies, with the aim of eliminating confounding factors. With regard to the association of urinary tract infections and urinary tract stones, as mentioned in many previous studies, it seems that due to the diuretic properties of this drug, it also helps to excrete stones and may prevent infection $(17,20)$.

Regarding to diuretic effect of this drug, it may help stone passage and may prevent the infection. In our study, despite the fact that in the two groups after treatment, most of the stones were passed or reduced in size, but the addition of hydrochlorothiazide did not significantly increase the rate of excretion or treatment, which may be due to the short duration of drug use or other factors such as calcium level of urine that was not measured in this study.

\section{Conclusion}

The results of this study showed that the combination of cystone and hydrochlorothiazide do not increase the efficacy of cystone in treatment and passage of urinary stones, although in both groups stone passage significantly increased. It is recommended that studies with larger sample sizes and different doses of cystone and hydrochlorothiazide be carried out with longer time, especially in larger stones.

\section{Limitation of study}

One of the limitations of the study was inappropriate access of patients to cystone drug during the study period, which was prepared in co-ordination with one of the pharmacies.

\section{Acknowledgments}

The authors are grateful to the respected vice president of the technical and research department of Yasuj University of Medical Sciences, for the provision of facilities for this project.

Authors' contribution

SM; the concept, design, data analysis, and manuscript 
preparation ,manuscript review and final revision. PB; performing experiments, data collection and writing proposal. LM; statistical analysis, data collection and first revision. AM; data collection and providing first draft and submission. All authors read and signed the final paper.

\section{Conflicts of interest}

The authors declared no conflicts of interest. The authors declare that, they had not receive any grant from drugs companies and it is only the result of authors' experiment.

\section{Ethical considerations}

Ethical issues (including plagiarism, data fabrication, double publication) have been completely observed by the authors.

\section{Funding/Support}

This manuscript was extracted from MD thesis of Parisa Behnam with IRCT number of IRCT20081011001323N15, and was supported financially by the deputy of research of Yasuj University of Medical Sciences.

\section{References}

1. Menon M, Resnick MI. Urinary lithiasis: etiology, diagnosis, and medical management, Campbell MF, Walsh PC, Retik $\mathrm{AB}$, eds. Campbell's Urology. (8th ed.). Philadelphia: Saunders; 2002. p. 3230-437.

2. Scales CD, Smith AC, Hanley JM, Saigal CS. Prevalence of kidney stones in the United States. Eur Urol. 2012;62:160-5. doi: 10.1016/j.eururo.2012.03.052.

3. Siener R, Glatz S, Nicolay C, Hesse A. Prospective study on the efficacy of a selective treatment and risk factors for relapse in recurrent calcium oxalate stone patients. Eur Urol. 2003;44:467-74.

4. Aghamohammadi H, Mehrabi S, Mohammad Ali Beigi F. Prevention of bradycardia by atropine sulfate during urological laparoscopic surgery: a randomized controlled trial. Urol J. 2009;6:92-5.

5. Sutherland JW, Parks JH, Coe FL .Recurrence after a single renal stone in a community practice. Miner Electrolyte Metab. 1985;11:267-9.

6. Gurocak S, Kupeli B: Consumption of historical and current phytotherapeutic agents for urolithiasis: a critical review. J Urol. 2006;176:450-5. doi: 10.1016/j.juro.2006.03.034.

7. Butterweck V, Khan SR. Herbal medicines in the management of urolithiasis: alternative or complementary?
Planta Med. 2009;75:1095-1103. doi: 10.1055/s-00291185719 .

8. Kumaran MGS, Patki PS. Evaluation of an ayurvedic formulation (cystone), in urolithiasis: a double blind, placebo controlled study. Eur J Integr Med. 2011;3:23-28

9. Karamakar D, Patki P. Evaluation of efficacy and safety of a herbal formulation Cystone in the management of urolithiasis: Meta-analysis of 50 clinical studies. Int J Altern Med. 2010; 8: 1-18.

10. Mohanty N, Nayak R, Patki P. Safety and efficacy of an ayurvedic formulation cystone in management of ureteric calculi: a prospective randomized placebo controlled study. Am J Pharm Toxicol. 2010;5:58-64.

11. Jeyaraman R, Mitra. Evaluation of the safety and efficacy of cystone liquid in the management of lower ureteric stones. Indian Journal of Urology. 2008;24: S49-S49.

12. Patki P, Shastry V, Jayaramaiah K, Agadihiremath T, Anturlikar S, Mohamed R. Cystone, a well-known herbal formulation, inhibits struvite crystal growth formation in single diffusion gel growth technique. J Exp Integr Med. 2013;3: 51. doi: 10.5455/jeim.101112.or.054.

13. Erickson SB, Vrtiska TJ, Lieske JC. Effect of cystone(R) on urinary composition and stone formation over a one year period. Phytomedicine. 2011;18: 863-7.

14. Alshahrani S, Soleimani M. Ablation of the Cl-/HCO3exchanger pendrin enhances hydrochlorothiazide-induced diuresis. Kidney Blood Press Res. 2017;42:444-55. doi: 10.1159/000479296.

15. Xu H, Zisman AL, Coe FL, Worcester EM. Kidney stones: an update on current pharmacological management and future directions. Expert Opin Pharmacother. 2013;14:43547. doi: 10.1517/14656566.2013.775250.

16. Yendt ER, Cohanim M. Prevention of calcium stones with thiazides. Kidney Int. 1978;13: 397-409.

17. Yosefi P, Cyrus A, Dorreh F, Rashidy S M. The effectiveness of Hydrochlorothiazide on preventing recurrent urinary tract infection in idiopathic hypercalciuric children. J Arak Uni Med Sci. 2006; 9:68-75.

18. Vigen R, Weideman RA, Reilly RF. Thiazides diuretics in the treatment of nephrolithiasis: are we using them in an evidence-based fashion? Int Urol Nephrol. 2011;43:813-9. doi: 10.1007/s11255-010-9824-6.

19. Choi JN, Lee JS, Shin JI. Low-dose Thiazide diuretics in children with idiopathic renal hypercalciuria. Acta Paediatr. 2011;100:71-4. doi: 10.1111/j.1651-2227.2011.02191.x.

20. Tiselius HG, Ackermann D, Alken P, Buck C, Conort P, Gallucci M. Guidelines on Urolithiasis1. Eur Urol. 2010; 40:362-71.

Copyright (C) 2019 The Author(s); Published by Nickan Research Institute. This is an open-access article distributed under the terms of the Creative Commons Attribution License (http://creativecommons.org/licenses/by/4.0), which permits unrestricted use, distribution, and reproduction in any medium, provided the original work is properly cited. 